\title{
Abstractness of the common element in mediated learning'
}

\author{
Allan Paivio and A. Dan Yarmey \\ UNIVERSITY OF WESTERN ONTARIO
}

\begin{abstract}
Abstraet
Concrete and abstract nouns differing in rated capacity to evoke imagery served as the common elements in a stimulus equivalence mediation paradigm. The mediation test items were nonsense syllables. Significant mediation effects were obtained in 2 experiments. Relative to control Ss, the concrete mediation group was superior to the abstract in rate of learning over mediation test trials, but not in total learning scores. Any influence of nonverbal (imaginal) mediation was apparently overshadowed by verbal chaining.
\end{abstract}

\section{Problem}

A series of studies has shown that paired-associate (PA) learning of nouns is facilitated by noun concreteness, this effect being consistently greater on the stimulus side of pairs (Paivio, 1965; Paivio \& Olver, 1964; Paivio, Yuille, \& Smythe, submitted ${ }^{2}$ ). These findings support the hypothesis that concrete, in comparison with abstract nouns, function as superior "conceptual pegs" for their associates because of their capacity to evoke sensory images which can mediate response recall (Paivio, 1963). The theory was more directly supported in the above studies by the findings that concrete nouns exceed abstract nouns in rated image-arousing capacity and that recall scores correlated more highly with stimulus imagery scores than with response imagery. The effect of imagery was shown to be independent of a correlated attribute, meaningfulness $(m)$. The present investigation tested an extension of the mediating-imagery hypothesis using an A-B, C-B, A-C (acquired stimulus equivalence) mediation paradigm (Jenkins, 1963) in which concrete and abstract nouns served as the common, $\mathrm{B}$, elements and nonsense syllables as $\mathrm{A}$ and $\mathrm{C}$ terms. We reasoned that, during the first two stages, not only would the nonsense syllables acquire the capacity to elicit the nouns as verbal responses, but that syllables paired with concrete nouns would acquire some image-evoking capacity through higher-order conditioning. Mediated learning of the nonsense syllables should thus be superior with concrete rather than abstract nouns as mediators. In view of Horton's (1964) finding that mediated association was strongly affected by $\mathrm{m}$ of the common element, and since we wanted to restrict any effects to differences in imagery, the concrete and abstract nouns were equated for $\mathrm{m}$ but differed in imagery.

\section{Experiment 1}

\section{Method}

Sixty university summer school students served as Ss. Fifteen were assigned in a random fashion in accordance with the S's order of appearance for the experiment to each of four treatments: concrete mediation, concrete control, abstract mediation, and abstract control. The mediation paradigm consisted of three stages, A-B, C-B, test A-C, where B consisted of concrete nouns for one group and abstract nouns for the other, and $\mathrm{A}$ and $\mathrm{C}$ were nonsense syllables. The sequence of lists for control groups was A-B, C-X, test $\mathrm{A}-\mathrm{C}$, where the $\mathrm{B}$ and $\mathrm{X}$ terms were different sets of concrete or abstract nouns. Each stage involved eight pairs. The nonsense syllables ranged from 80 to $86 \%$ association value (Kreuger, in Underwood \& Schulz, 1960). The $B$ and $X$ terms consisted of 16 concrete (e.g., umbrella, star, elephant) and 16 abstract (e.g., comedy, health, effort) nouns selected from those previously used by Paivio (1964) and Paivio et al (submitted), on which were available $\mathrm{m}$ scores and ratings of the ease (latency) with which they elicit imagery. The nouns were highly familiar, were equated for $\mathrm{m}$, but all the concrete nouns exceeded the abstract in imagery. The assignment of nouns to mediation (B) or non-mediation (X) conditions was random.

Standard instructions for the anticipation method of PA learning were given to each S. The lists were presented at a 2:2 sec. rate on a memory drum, with a 12-sec. intertrial interval and a 3-min. interval between lists. Lists $1(\mathrm{~A}-\mathrm{B})$ and $2(\mathrm{C}-\mathrm{B})$ were learned to a criterion of two consecutive errorless trials; the test list (A-C) was presented for four anticipation trials. Four randomizations of the position of pairs in each list were employed to prevent serial learning. Prior to learning the significant units, each $\mathrm{S}$ had four practice trials on eight adjective-numeral pairs.

\section{Results}

The means of the number of correct anticipations on each of the four test trials for each group are shown in the left-hand part of Fig. 1. An analysis of variance of these data yielded a significant effect of trials $(\mathrm{F}(3,168)=59.18 ; \mathrm{p}<.001)$ and superiority of mediation over control conditions $(F(1,56)=14.39 ; \mathrm{p}<.01)$. An insignificant interaction of conditions $\mathrm{x}$ noun abstractness $(F=0.04)$ indicated no overall superiority of concrete mediators; however, a significant interaction of trials $x$ conditions $x$ abstractness $(F(3,168)=4.52$; $\mathrm{p}<.005)$ revealed a faster rate of learning by the concrete than by the abstract mediation group. This is confirmed by $t$ tests between control and mediation group means at trials 1 and 4 . At trial 1, the abstract mediation group mean significantly exceeds their control mean $(t(28)=3.87 ; p<.001)$, but the same comparison is 


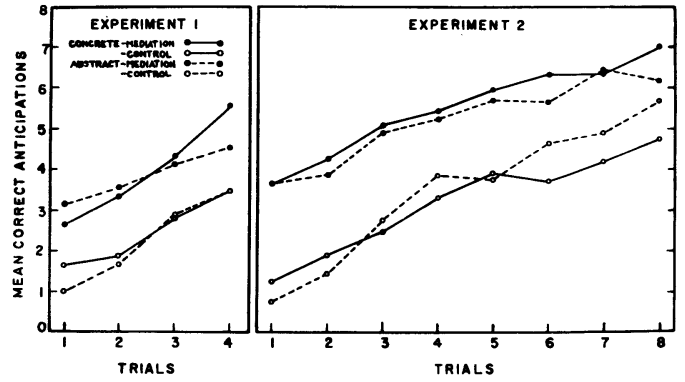

Fig. 1. Mean number of correct anticipations for concrete and abstract, mediation and control groups over the 4 trials in Experiment 1, and 8 trials in Experiment 2.

insignificant for the concrete groups $(t=0.82)$. Conversely, at trial 4 the concrete mediation group surpasses their control $(t(28)=4.02 ; p<.001)$, whereas the abstract does not $(t=1.54)$. These data suggested that the expected superiority of concrete over abstract mediation might have been clearer with a larger number of test trials. Accordingly, the experiment was repeated using eight rather than four trials in the test stage.

\section{Method}

\section{Experiment 2}

The Ss were 40 male and 40 female introductory psychology students. The design was similar to that of Experiment 1 except that eight rather than four anticipation trials were used in the test stage. Equal numbers of each sex were randomly assigned to each condition. The test items were the same as those used in Experiment 1.

\section{Results}

The means of the number of correct anticipations for each condition over the eight trials are shown in the right-hand portion of Fig. 1. An analysis of variance again showed a significant trials effect $(F(7,504)=113.59 ; p<.001)$, superiority of mediation over control conditions $(F(1,72)=64.07 ; p<.001)$, no interaction of conditions $x$ noun abstractness $(F=1.40)$, but a significant interaction of trials $x$ conditions $x$ abstractness $(F(7,504)=2.78 ; p<.01)$. To permit further comparisons with Experiment 1, $t$ tests between mediation and control groups were done at trials 1,4 , and 8 . The concrete mediation group exceeded the control at each point (ts $=6.54,4.09$, and 4.42; $\mathrm{df}=38 ; \mathrm{p}<.001$ in each case), whereas the abstract mediation group exceeded their control at trials 1 and 4 (ts $=6.22$, and 3.30; $\mathrm{p}<.001)$ but not at trial $8(t=1.18)$, indicating that rate of learning was again faster when the mediators were concrete rather than abstract.

\section{Diseussion}

Although the results of the two experiments differ in detail, they agree in showing a faster rate of learning under concrete than under abstract mediation conditions, relative to the respective controls, but no overall superiority favoring the former. Thus, the effect of concreteness and imagery of the mediating element is positive but slight in comparison with the effect of $m$ observed by Horton (1964), at least for the stimulus equivalence paradigm. An explanation is suggested by considering the mediation data together with the effects of the above variables in ordinary PA learning. Concreteness and imagery facilitate PA learning more on the stimulus than the response side of pairs (e.g., Paivio, 1965), whereas $\mathrm{m}$ is consistently more effective on the response side (see Underwood \& Schulz, 1960). That $\mathrm{m}$ of the implicit mediator also affects mediate association whereas imagery is relatively ineffective is therefore consistent with the interpretation that such mediation is mainly a response process (cf. Horton \& Kjeldergaard, 1961; Jenkins, 1963) involving implicit verbal chaining rather than a nonverbal representational process such as imagery. However, the results do not preclude the possibility of stronger effects attributable to conditioned imagery if objects rather than words were used as the common elements.

\section{Referenees}

HORTON, D. L. The effects of meaningfulness, awareness, and type of design in verbal mediation. J. verbal Learn. verbal Behav., $1964,3,187-194$.

HORTON, D. L., \& KJELDERGAARD, P. M. An experimental analysis of associative factors in mediated generalizations. Psychol . Mongr., 1961, 75, No. 11 (Whole No. 515).

JENKINS, J. J. Mediated associations: Paradigms and situations. In C. N. Cofer and B. S. Musgrave (Eds.), Verbal behavior and learning. New York: McGraw-Hill, 1963. Pp. 210-245.

PAIVIO, A. Learning of adjective-noun paired-associates as a function of adjective-noun word order and noun abstractness. Canad. J. Psychol., 1963, 17, 370-379.

PAIVIO, A. Abstractness, imagery, and meaningfulness in pairedassociate learning. J. verbal Learn. verbal Behav., 1965, 4, in press.

PAIVIO, A., \& OLVER, M. Denotative-generality, imagery, and meaningfulness in paired-associate learning of nouns. Psychon. Sci., 1964, 1, 183-184.

PAIVIO, A., YUILLE, J., \& SMYTHE, P. Stimulus and response abstractness, imagery, and meaningfulness, and reported mediators in paired-associate learning. (Submitted)

UNDERWOOD, B. J., \& SCHULZ, R. W. Meaningfulness and verbal learning. Chicago: Lippincott, 1960.

\section{Notes}

1. This research was partially supported by grants to the first author from the National Research Council of Canada (Grant APA-87) and the University of Western Ontario Research Fund.

2. A pre-publication copy of the article cited as "submitted" may be obtained by writing to the first author. 